\title{
EFL Writing Skills Development Through Literature
}

\author{
Dr. Siham BOUZAR FODIL-CHERIF \\ University of Algiers 2, Algeria \\ E-mail: sissifch@gmail.com
}

Received: May 2, 2021 Accepted: July 2, $2021 \quad$ Published: July 3, 2021

doi:10.5296/elr.v7i2.18835 URL: https://doi.org/10.5296/elr.v7i2.18835

\begin{abstract}
Learning another language as English requires a combination of knowledge of the target language with skills and strategies that enable an individual to use them effectively. That is a learner has to develop knowledge about receptive skills; i.e., listening and reading, as well as productive ones; i.e., speaking and writing. Though all the skills are important for language learning, the writing skill is probably the most needed in academic and professional communities. It constitutes an important means of communication through which the writer expresses feeling, ideas and arguments. In the case of English language learning, writing in a language that one is not familiar with constitutes a hard task. In fact, though writing represents a crucial skill for learning any language, its complex nature makes it a challenging affair for both the learners and the teachers. It requires the learners to be guided and assisted in their efforts to reach success. Besides, the teachers are expected to furnish the appropriate measures to achieve the teaching goals. Therefore, it is with the perspective to highlight the importance of writing and the role of reading literature in developing EFL learners' writing skill that this piece of work is undertaken. This is achieved via disclosing the nature of the writing skill and how the implementation of literature in the writing classes can provide positive effect on EFL learners' performance.
\end{abstract}

Keywords: Writing skills, Reading literature, Teaching EFL learners

\section{Introduction}

Attaining proficient literacy is a goal that any EFL learner strives to reach. This objective constitutes a real hurdle facing both learners and teachers mainly when it concerns writing skill. The latter requires not only a mastery of the language system but also a mastery of the writing techniques necessary to the achievement of a coherent, organized and a comprehensible message. This can be realised by involving learners in reading literary texts that would facilitate the process of gaining writing proficiency. Thus, a general outlook about the writing skill as well as the diverse connections between reading literary texts and writing skill are discussed. Likewise, since EFL learners are required to master both the structural 
and the communicative aspects of the language, a presentation concerning integrating literary texts as a resource in the EFL writing classroom is highlighted.

\section{The Nature of Writing}

Writing as a means of communication had been attributed various definitions. According to the Online Encyclopaedia of Writing Systems and Languages, "writing is a method of representing language in visual or tactile form. Writing systems use sets of symbols to represent the sounds of speech, and may also have symbols for such things as punctuation and numerals". However, writing cannot be limited to orthography symbolisation of speech as it extends it to reach purposeful selection and organisation of expressions (Brooks 1960) according to the conventions of the target language. The latter concern grammar, vocabulary, handwriting, spelling, layout and punctuation (Harmer, 2001). Equally important aspect of writing is crafting which Hedge (1988:89) explains it as "the way in which a writer puts together the pieces of the text, developing ideas through sentences and paragraphs within an overall structure".

Research in the field of writing revealed that this skill is very complex as it encompasses multitude of processes to reach the final product. It is not a mere representation of ideas, but it is the exhibition of multiple processes in which the writer gets involved namely cognition, problem solving and social connection.

\subsection{Writing as a Cognitive Process}

The human's brain enables people to engage in various activities while attempting to write something. It enables them to explore the world around them, analyze it and then translate it by selecting an appropriate language. In this regard, Sinclair (2010) mentions that skilled writers show a strong sense of observation, and that the latter allows them not only to get a considerable knowledge content but also to establish a link between speech and writing. Blamires (2003) notes that human beings make sense of the world surrounding them via abstract mental structures called the schemata which represents their knowledge of things, events and situations. Blamires also underlines the fact that some difficulties can be encountered when reading or writing texts in a non-native language because of the culture-specific nature of schemata.

\subsection{Writing as a Problem Solving Process}

As a complex skill, writing involves the consideration of various variables: the linguistics knowledge and writing techniques need to be combined with the awareness of subject, purpose and audience. Silva (1990) points out that "writing is basically a matter of arrangement, of fitting sentences and paragraphs into prescribed patterns. Learning to write then, involves becoming skilled in identifying, internalizing, and executing these patterns" Thus, a skilful writer would take these elements into account and think of appropriate strategies that would fit the writing purposes.

Additionally, Kern (2000) believes that writing is an active process requiring active thinking and problem solving. That is the writer has to make a connection between the schemata and the new elements to create new knowledge structures. Yet, this creativity would not take place unless cultural knowledge of the society addressed is acquired. 


\subsection{Writing as a Social Process}

Writing as a process occurs within a context that dictates which particular process to be followed the writer. In fact, there are different steps to follow to write a meaningful piece of work. These stages namely planning, drafting and revising are common stages that each individual goes through, yet this cycle is flexible. That is depending on the context, "writers are immersed, they may decide what steps to take or follow in a particular process, so they may begin to revise at the moment they think about what to do, and some others immediately draft their ideas as they are generating them" (Camps, 2017: 15).

Another aspect that should be considered when involved in the writing process is the feelings that the students may experience as they are writing. For instance, the demands placed upon students in terms of genres and their conventions, the time attributed to the task and the number of words limit may affect their written production. The worries and anxiety that they may experience make them write in a different way than when they are at ease. Thus, it can be said that writing practices are social processes because they derive from the circumstances surrounding the writer.

\section{The Importance of Writing}

Though writing represents a crucial skill for learning any language and constitutes an important means in communication, the place that is attributed to it in our daily life reflects that it is neglected. This idea has been emphasised by lot of researchers. For instance, Allen (1995) underlined this aspect on the ground of statistical calculations. According to him, "the largest portion (40\%) of our daily communication is devoted to listening, with thirty five (35\%) being dedicated to speaking, sixteen (16\%) is devoted to reading and only nine $(09 \%)$ is occupied by writing" (ibis: 02). Therefore, raising learners' awareness about the importance of this skill in the process of learning the target language requires to be emphasized.

In fact, writing is essential in our lives as it brings many advantages. According to Chappell, (2011), writing helps to express one's personality; fosters communication and develops thinking. Besides, Klimova (2013) puts stress on the benefits that can be retrieved from writing. According to her, writing as a productive skill help to "make logical and persuasive arguments, give a person a chance to later reflect on his/her ideas and re-evaluate them, provide and receive feedback and prepare for school and employment" (ibis: 09). Additionally, Walsh (2010), stresses the importance of writing as it is extensively needed in academic and professional communities. In fact, the majority of the communications taking part in our daily life or professional one is realised via writing. The use of this important skill can be witnessed in various instances such as writing proposals, memos, reports, applications, e-mails and many othe examples where written messages are required. Thus, if learners do not know how to express their ideas clearly with their professors and peers, they will fail later in communicating with their employers and colleagues as the message that needs to be transmitted will not reach its audience properly.

Mastering a language requires the mastery of the four skills which constitute the pillars of any language learning. Writing as a productive skill can not be dissociated from the other skills, and mastering it needs lot of practice and a combination of cognitive and metacognitive strategies. Therefore, giving a chance to learners to produce free pieces of work will wake up their 
creativity and develops their writing skill. In this framework, Maley (2009) lists the multiple benefits that creative writing can bring. According to this scholar, it aids language development at all levels: grammar, vocabulary, phonology and discourse as it requires learners to manipulate the language in amazing and interesting ways as they attempt to express their feelings and ideas. Likewise, creative writing is said to increase self confidence and self esteem among learners who have a tendency to uncover hidden things about the language and about themselves too, hence it promotes personal and linguistic growth as well as motivation to continue writing. Finally, creative writing leads to increase reading among the learners. It is by getting in the process of writing that learners get better understanding of how texts are constructed which leads them to read more so that to implement similar structures in their texts.

\section{Writing Difficulties}

Writing as a skill reflects the learner's mastery of language and ability to express his ideas in a correct and coherent way. Since it is a challenging task, EFL learners encounter several obstacles namely grammar, vocabulary, interference and other factors when engaged in the process of writing.

As concerns grammar, Harmer (2001) gave a detailed definition in which he referred to grammar as "the description of the ways in which words can change their forms and can be combined into sentences in that language" (p. 12). Students who lack knowledge about the rules of the target language will face difficulties in writing correct texts and coherent ones. Grammar rules mostly incorporate different standards that learners must have control on them such as tenses, prepositions, adverbs. Therefore, considering this important element of language use is necessary.

Regarding the use of vocabulary is regarded as one of the main hurdles facing EFL learners. While writing, the choice of the appropriate words fitting the ideas they want to express becomes a real challenge that needs to be faced. In fact, in their process of learning, they meet plenty of words. Some of them are common to them which they use without any problem while others constitute a challenge as they are new words that they ignore their meanings or ambiguous ones that that their essence is still unclear. In this context, Seely (1998) lists significant components in vocabulary issue namely active, passive, new and ambiguous. The first one is linked words that are commonly used by learners in their writing. The second type refers words understood by the learners but not used in writing. The third item concerns words that have never been dealt with; and the last type of vocabulary is related to the linguistic items which were seen before, but their meaning is ambiguous.

With regard to spelling, Yakhontova (2003: 61) claims that "English spelling is rather difficult and irregular". She adds, "In academic writing, spelling should always be consistent, either American or British throughout". In this regard, proof reading is essential for academic writing, which is based on finishing a piece of writing, reading it, detecting mistakes and adjusting them. This procedure will be simpler given that the writer checks the spelling while processing the texts.

With reference to punctuation, the latter is considered as an additional challenge to the writer who is compelled to master its rules. It plays a great role in attributing meaning to the written text. That is any use of punctuation marks in a wrong place will lead to change the meaning 
of the transmitted message, hence misleading the reader. This idea had been underlined by by Seely (1998: 229) who claims that "the person who has learned how to use commas has learned how to write". Thus, knowing where and how to punctuate means that the writer understands well his/her ideas and is able to transform them into a written products.

The last obstacle that may face EFL writers is first language interference. It is perhaps the most difficult issue that can hinder students' writing. Indeed, this issue arises when the learner tries to apply their knowledge from their native language to the foreign one which results in the deviation of the intended meaning. This phenomenon is unavoidable as it is linked with the way the target language is learnt and the extent to which the writer is knowledgeable about the target culture. Besides, translating an idea from the mother language to the target one will alter the whole meaning of the message. Unfortunately, such interference often leads to inaccuracy and ambiguity of the written texts.

\section{The Intersection Between Reading Literary Texts and Writing}

Good writing is unlikely to happen without deep reading. In fact students cannot produce any piece of writing without being exposed to effective models of written texts. The documents that they go through help in "making the invisible visible" (Schoenbach et al., 2012: 23). They will enable them to notice and analyze the author's text and how ideas are presented in a way that makes them apply those techniques in their own writing. In this context, King (2017) notes the value of reading literary texts. The latter according to him teach "the learning writer about style, graceful narration, plot development, the creation of believable characters, and truth telling" (ibid, 211).

Therefore, it can be said that there exists a tight link between reading and writing. They intersect in many ways. First of all, reading can be considered a crucial element to writing in terms of information supply. That is, students need to understand a topic and make research about it before starting writing about it. Besides, students who read in many genres usually have huge command of vocabulary and develop a subconscious capacity in using correct grammar and punctuation without receiving instruction about the rules. Through reading, learners internalize how vocabulary and structures function in the text. They are "exposed to language patterns that help them to see the many and complex ways that sentences and paragraphs can be put together" (Vandrick, 2003, p. 265). Furthermore, writers require deeper knowledge of the subject to be dealt with. This knowledge cannot be attained unless it is gathered from scholarly articles and books in print or online.

In the same context, literary texts provide a rich source to the learners to exploit in their writing and uncover how language functions. They contain authentic examples of grammatical structures and vocabulary items that would raise students' awareness about the features of the written language in terms of sentence structure, form variety and ideas connection besides extending their vocabulary use (Pardede, 2011; Vandrick, 2003).

Additionally, reading literary texts opens learners' eyes on the socio-cultural aspect of other communities. Indeed, an interaction with literary texts will not only allow learners to acquaint the language system but also enable them to get to know a community's beliefs and practices. Hence, lack of familiarity with the cultural background of the text will lead to misinterpretation and failure in transmitting ideas in an appropriate way (Steffenson and 
Joag-dev, 1992).

\section{Criteria for Selecting Literary Texts}

Gaining proficiency in writing requires exposure to a number of literary texts. With the perspective to develop this skill, research had been undertaken to understand and improve learners' ability to produce comprehensible texts. Krashen (1989) for instance, states that "reading exposure is the primary means of developing language skills" (Krashen, 1989: 109). According to him, it is essential to make learners interact with authentic language from written pieces of work to develop not only their writing skill but also the other ones as reading, speaking and listening. Likewise, with reference to Krashen's Input Hypothesis (1985), exposing learners to linguistic input which is slightly beyond the learners' competence (input+1) is one way to improve this skill. In the same framework, Lazar (1993) advises the use of short texts that suit the learners' level and can keep them focused. Besides, MacRae (1991) suggests the selection of texts encouraging the discovery of the outside world via the world of ideas. The selection of literary texts to Nunan (1991) should "affirm, confirm and expand one's capacity to read the world" (p. 35).

The selection of the literary material that would promote writing proficiency is based on three criteria as suggested by Lazar (2007). These have to do with the type of course, the type of students, and the other text related factors.

As concerns the first criterion, the type of course deals with the objectives of the course that the students are expected to perform. In this respect, the teacher has to consider the language average level of his students to select the literary material successfully. The teacher needs also to collect information about the reason behind learning the target language to keep the learners motivated. Additionally, the length and intensity of the course needs to be considered so that the selected material would not fit the allocated time.

With respect to the second criterion, the type of students the teacher is about to deal with is quite important as each element of the information collected will play a role in enhancing or decreasing the learning process. In other words, having knowledge about the students' age, intellectual maturity and emotional understanding will facilitate the task to the teacher to select appropriate learning materials that engage the students emotionally and intellectually. It is also important to consider the students' cultural background to avoid confusion towards the learning materials.

The last criterion in connection with other text-related factors is mainly linked to the availability of the text and whether the students can have access to it. Another aspect to consider is whether the literary text can be exploited in terms of devising tasks and activities. Finally, it is essential to the teacher to choose the materials that fit with the syllabus objectives.

\section{Conclusion}

Writing represents a crucial skill for learning any language. It involves the ability to transmit and receive information, develop and support a point of view, and underline other facets of the outside world in terms of culture and beliefs. Its complex nature makes it a challenging affair for both the learners and the teachers. It requires the learners to be guided and assisted in their efforts to reach success. Besides, the teachers are expected to furnish the appropriate 


\section{Macrothink}

Education and Linguistics Research ISSN 2377-1356 2021, Vol. 7, No. 2

measures to achieve the teaching goals. Thus, in this piece of work, we tried to highlight the importance of the writing skill and how it can be promoted via the implementation of reading literary texts in the language classroom.

\section{References}

Allen, M. B. (1995). Listening: the Forgotten Skill. A Self Teaching Guide. Wiley Publishing Company.

Camps, D. (2017). A Discussion of the Social Nature of the Writing Process. Revista de Clase Internacional, 4(8), 15-19.

Chappell, V. (2011). What makes writing so important? Retrieved December 27, 2012, from http://www.marquette.edu/wac/

Harmer, J. (2001). The Practice of English Language Teaching. London: Longman Harmer. https://doi.org/10.1177/003368820103200109

King, S. (2017). Reading to Write. 50 Essays: A Portable Anthology, In S. Cohen (ed.), Bedford / St. Martin's.

Klimova, B. F. (2013). The Importance of Writing, Indian Journal of Research, Paripex, pp 9-11. https://doi.org/10.15373/22501991/JAN2013/4

Krashen, S. (1989). Language Acquisition and Language Education. UK: Prentice HallInternational.

Krashen, S. (1985). The Input Hypothesis: Issues and Implications. New York: Longman.

Lazar, G. (1993). Literature and Language Teaching, a Guide for Language Teachers and Trainers. Cambridge: Cambridge University Press. https://doi.org/10.1017/CBO978051 1733048

Lazar, G. (2007). Literature and Language Teaching. Cambridge: CUP.

Macrae, J. (1991). Literature with a Small “L”. London: Macmillan.

Maley, A. (2009). Creative Writing for Language Learners and Teachers. Retrieved April 12, 2011, from http:/www.teachingenglish.org.uk/think/articles/creative-writing-languagelearners-teachers

Nunan, D. (1991). Designing Tasks for the Communicative Classroom. Cambridge: Cambridge University Press

Pardede, P. (2011). Using Short Stories to Teach Language Skills. Journal of English Teaching, 1(1). https://doi.org/10.33541/jet.v1i1.49

Schoenbach, R. (2012). Reading for Understanding: How Reading Apprenticeship Improves Disciplinary Learning in Secondary and College Classrooms. Jossey Bass.

Seely, J. (1998). The Oxford guide to effective writing and speaking. Oxford: Oxford University Press. 
Steffenson, S., \& Joag-dev, C. (1992). Cultural Knowledge and Reading. In Reading in a Foreign Language. NY: Longman.

Vandrick, S. (2003). Literature in the Teaching of Second Language Composition. In B. Kroll (Ed.). Exploring the Dynamics of Second Language Writing. Cambridge: Cambridge University Press. https://doi.org/10.1017/CBO9781139524810.017

Walsh, K. (2010). The Importance of Writing Skills: Online Tools to Encourage Success. Retrieved December 27, 2012, from http://www.emergingedtech.com

Yakhontova, T. (2003). English academic Writing for Students and Researchers. AIvan Franko: National University of Lviv.

\section{Copyright Disclaimer}

Copyright reserved by the author(s).

This article is an open-access article distributed under the terms and conditions of the Creative Commons Attribution license (http://creativecommons.org/licenses/by/4.0/). 